\title{
Magnetic properties of nanocomposites of mixed oxides of iron and chromium synthesized under different oxidative environments
}

\author{
RASHI MATHUR, D R SHARMA, S R VADERA and N KUMAR* \\ Defence Laboratory, Jodhpur 342011 , India \\ MS received 15 February 1999; revised 19 July 1999
}

\begin{abstract}
Synthesis of nanocomposites of mixed oxides of $\mathrm{Fe}$ and $\mathrm{Cr}$ in a copolymer matrix of aniline and formaldehyde at room temperature along with IR, XRD and ${ }^{57} \mathrm{Fe}$ Mössbauer studies on as synthesized as well as the samples on heating at different temperatures is described. The XRD and ${ }^{57}$ Fe Mössbauer studies show the formation of nanosized iron oxide particles. These studies further show the formation of nanosized particles of metal oxides and formation of solid solution of iron and chromium oxide on heating the samples at $700^{\circ} \mathrm{C}$. Further, the IR studies show that the polymeric backbone is strongly influenced by different reaction conditions and lead to variable magnetic character in the heated samples as shown by their Mössbauer studies.
\end{abstract}

Keywords. Nanocomposites; copolymer; solid solution; oxidants; X-ray diffraction; Mössbauer spectroscopy; infrared spectroscopy.

\section{Introduction}

The field of nanomaterials is becoming increasingly important as it provides great opportunities for tailoring of the materials with new, exciting and tunable physical and chemical properties. The nanomaterials can be polycrystalline or amorphous in nature and may belong to inorganic, organic or combination of both classes of materials (Shull 1992). The nanocomposites are one of the very important class of nanomaterials. They can be distinguished from the nanocrystalline and nanophase materials on the basis that in case of nanocrystalline/ nanophase materials only one phase exists, while in the case of nanocomposites more than one Gibbsian solid phases are present and out of which at least one of the phases is in the nanometer size range (Komarneni 1992). Several synthetic routes have been reported for the synthesis of nanocomposite materials. They include physical, chemical and biomimicking in nature (Chow and Gonsalves 1996). Most of the physical methods are sophisticated and require costly equipments to produce nanomaterials. However, biomimetic and wet chemical methods are relatively simple but most of them are unable to give these materials in bulk quantities.

Recently, an interesting chemical route (Pramanik 1995) has been reported to prepare nanoparticles of inorganic oxides by using polymeric materials. More recently, a novel route for room temperature synthesis of nanocomposites of mixed oxides of some d-block elements in a copolymer matrix has been developed in

*Author for correspondence this laboratory (Vadera et al 1997a) which has been found to be successful in giving materials in bulk quantities and is useful for the preparation of other nanocomposites. The present work reports the in situ direct synthesis of nanocomposites by employing mixed oxides of iron and chromium in the aniline-formaldehyde copolymer matrix at room temperature in the presence of different oxidants. Results of X-ray diffraction, ${ }^{57} \mathrm{Fe}$ Mössbauer and FTIR studies on as prepared samples and the samples heated at different temperatures up to $700^{\circ} \mathrm{C}$ are also presented here.

\section{Experimental}

\subsection{Synthesis}

The synthesis of nanocomposites has been described elsewhere (Vadera et al 1998). As a typical preparation, the sample RS3 nanocomposite of $\mathrm{Fe} / \mathrm{Cr}$ oxide was synthesized by treating the aqueous solution of aniline $(0.10 \mathrm{~mol})$, hydrochloric acid $(0.12 \mathrm{~mol})$, formaldehyde $(0.10 \mathrm{~mol})$ with an aqueous solution of halides of iron $(0.04 \mathrm{~mol})$ and chromium $(0.03 \mathrm{~mol})$ taken in a fixed molar ratio. To this ammonium peroxydisulphate $(0.0087 \mathrm{~mol})$ was added as an oxidant. The resulting mixture was stirred thoroughly and then added to $10 \%$ solution of $\mathrm{NaOH}$. The precipitated composite so obtained was washed with distilled water repeatedly till the filtrate was free of alkali $(\mathrm{pH} \mathrm{7.5)}$ and dried in air. Samples RS1-RS6 described in table 1, were prepared following the similar procedure by varying the oxidative environments while keeping the same copolymer backbone of aniline and formaldehyde. 


\subsection{Physical measurements}

The IR spectra were recorded in $\mathrm{KBr}$ medium using Shimadzu model 8000 FTIR spectrophotometer in the frequency range $4600-400 \mathrm{~cm}^{-1}$. The heating of the samples at $300^{\circ} \mathrm{C}, 450^{\circ} \mathrm{C}$ and $700^{\circ} \mathrm{C}$ was done in air in a furnace for one hour. X-ray diffractograms were recorded in the $2 \theta$ range of $20-60^{\circ} \mathrm{C}$ on Phillips Model PW 3710 diffractometer using $\mathrm{CuK}_{\alpha}$ radiations. ${ }^{57} \mathrm{Fe}$ Mössbauer spectra were recorded at room temperature in standard transmission geometry. The fitting of the spectra were done by using a computer programme (Meerwall 1975) by assuming the lines to be Lorentzian in shape.

\section{Results and discussion}

\subsection{FTIR studies}

The IR spectra of the samples prepared at room temperature are given in figure 1. It can be seen from the

Table 1. Reaction conditions for the synthesis of samples RS1-RS6.

\begin{tabular}{lccc}
\hline Sample & $\begin{array}{c}\text { Conc. of } \mathrm{FeCl}_{3} \\
\text { (moles) }\end{array}$ & $\begin{array}{c}\text { Conc. of } \mathrm{CrCl}_{3} \\
\text { (moles) }\end{array}$ & $\begin{array}{c}\text { Conc. of oxidant } \\
\text { (moles) }\end{array}$ \\
\hline RS1 & 0.061 & - & - \\
RS2 & 0.04 & 0.03 & - \\
RS3 & 0.04 & 0.03 & $\left(\mathrm{NH}_{4}\right)_{2} \mathrm{~S}_{2} \mathrm{O}_{8}(0.0087)$ \\
RS4 & 0.04 & 0.03 & $\mathrm{H}_{2} \mathrm{O}_{2}(0.127)$ \\
RS5 & 0.04 & 0.03 & $\mathrm{KMnO}_{4}(0.0253)$ \\
RS6 & 0.04 & - & $\mathrm{K}_{2} \mathrm{Cr}_{2} \mathrm{O}_{7}(0.014)$ \\
\hline
\end{tabular}

figure that in the IR spectrum of sample RS1 a broad peak is present at $600 \mathrm{~cm}^{-1}$ due to iron oxide (Mathur et al 1998), which shifts to lower frequencies and broadens further in case of samples RS2-RS6. This shift can be attributed to the presence of oxides of both iron and chromium in the samples RS2-RS6. Further, in case of samples RS1 and RS2, prepared in the absence of any oxidant, a similar absorption pattern is observed in the region $1700-1000 \mathrm{~cm}^{-1}$ whereas for samples RS3-RS6 there is substantial shift and broadening of peaks in this region. We know that the peaks in the region 1700$1000 \mathrm{~cm}^{-1}$ are mainly due to the copolymer backbone (Vadera et al 1997b). The observed variations in the IR spectra of the samples RS3-RS6 in this region may be attributed to the formation of either of the following two species because of the influence of the oxidative environment on the polymer backbone.

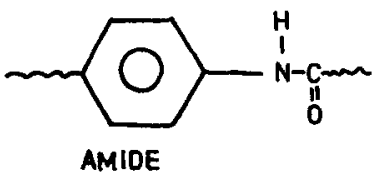

(1)

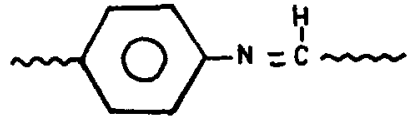

SCHIFF BASE

(II)
In case of the samples heated at $450^{\circ} \mathrm{C}$ (figure 2), the polymer part is almost removed as a result of combustion and the absorption peaks due to metal oxides are better resolved. The IR spectrum of sample RS1 shows two peaks at $545 \mathrm{~cm}^{-1}$ and $470 \mathrm{~cm}^{-1}$, due to iron oxide, while in samples RS2-RS6, containing both iron and chromium, we observe absorption peaks i.e. peaks $590-570 \mathrm{~cm}^{-1}$ and

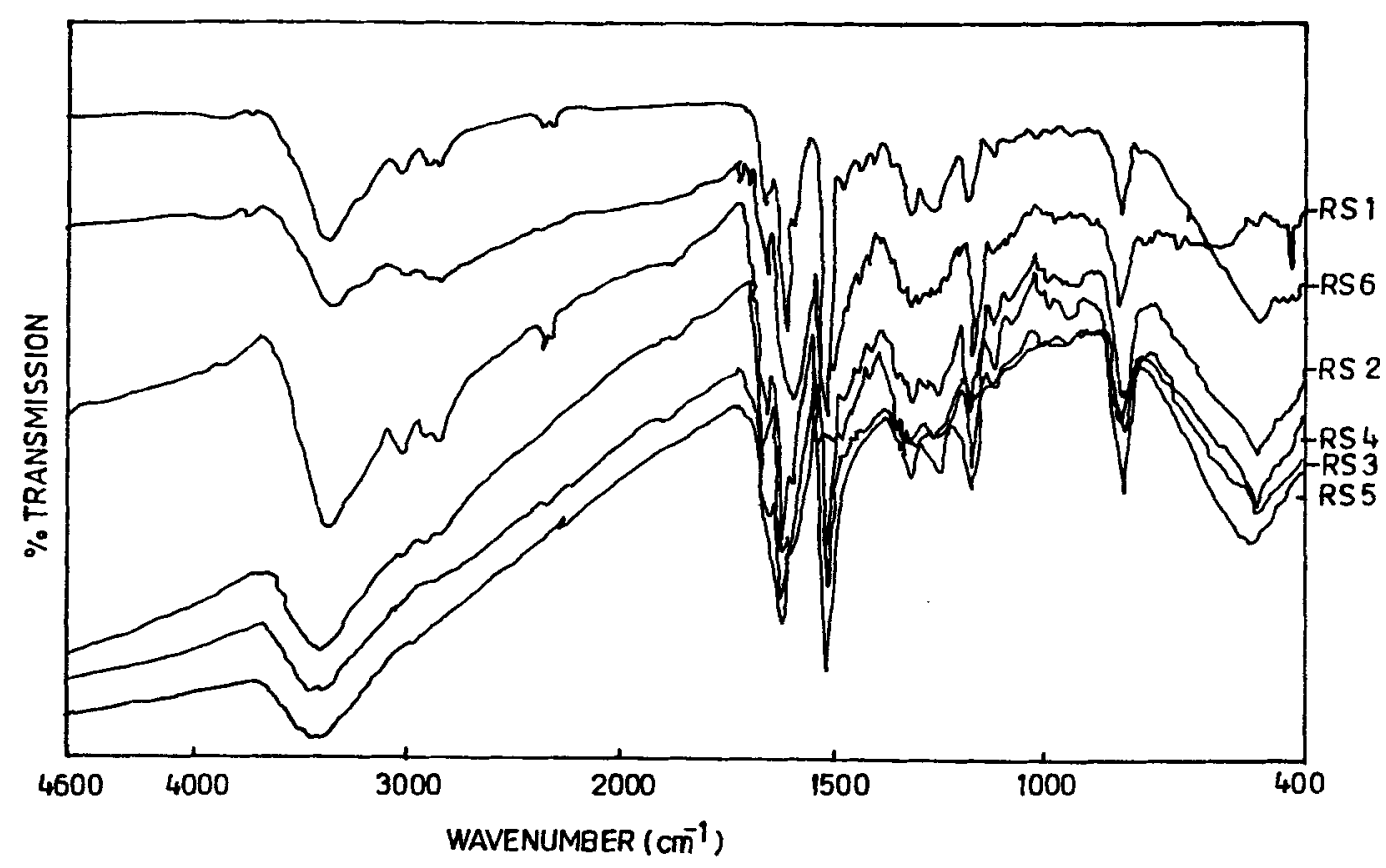

Figure 1. IR spectra of samples RS1-RS6 (of as prepared samples). 
$495-470 \mathrm{~cm}^{-1}$ due to $\gamma-\mathrm{Fe}_{2} \mathrm{O}_{3}$ and a peak at $648 \mathrm{~cm}^{-1}$ due to $\mathrm{Cr}_{2} \mathrm{O}_{3}$ (Bentley et al 1968). Further, variations in absorption peaks due to iron oxide, in samples RS2-RS6, may be attributed to varying degrees of interactions between $\mathrm{Fe}^{3+}$ and $\mathrm{Cr}^{3+}$ ions which in turn might be consequence of the changes in the polymer backbone by different oxidative environments, in the initial samples. From the IR spectra of samples heated at $700^{\circ} \mathrm{C}$ (figure 3), further broadening of the metal oxide peaks is observed in samples RS2-RS6. This very unique behaviour may arise because of the increased solubility of $\mathrm{Cr}_{2} \mathrm{O}_{3}$ in $\gamma-\mathrm{Fe}_{2} \mathrm{O}_{3}$ due to their small size effects (Johnson et al 1986). This observation thus indicates the formation of the solid solution in samples RS2-RS6 on heating at $700^{\circ} \mathrm{C}$.

\section{$3.2 X R D$ studies}

From the X-ray diffraction studies, the metal oxides in unheated samples RS1-RS6 were found to be amorphous, while on heating the samples RS2-RS6 at temperatures $\geq 300^{\circ} \mathrm{C}$, were found to be crystalline in nature. The observed diffraction peaks were indexed to identify different phases present in the samples. XRD spectra of the samples RS1-RS6, heated at $300^{\circ} \mathrm{C}$, are shown in figure 4 . From the figure we observe a very broad peak at $2 \theta$ value of $35.7^{\circ}(d=2.51 \AA)$ which corresponds to the strongest diffraction peak due to spinel $\gamma-\mathrm{Fe}_{2} \mathrm{O}_{3}$ ( $\mathrm{Li}$ et al 1998). The broad peak indicates that the size of $\gamma-\mathrm{Fe}_{2} \mathrm{O}_{3}$ particles is very small. The particle size was calculated by using Scherrer equation (Azaroff and Buerger 1958) and has been found in the range $10-15 \mathrm{~nm}$. The diffraction peak at $2 \theta$ value of about $33.2^{\circ}(d=2.69 \AA)$, the strongest peak of $\mathrm{Cr}_{2} \mathrm{O}_{3} / \alpha-\mathrm{Fe}_{2} \mathrm{O}_{3}$ phase (Bhattacharya et al 1997), is not observed in any of the samples. Further, the XRD spectra of all the samples heated at $450^{\circ} \mathrm{C}$, given in figure 5 , show the presence of diffraction peaks due to both $\gamma-\mathrm{Fe}_{2} \mathrm{O}_{3}$ and $\mathrm{Cr}_{2} \mathrm{O}_{3} / \alpha-\mathrm{Fe}_{2} \mathrm{O}_{3}$ except for samples RS5 where $\mathrm{KMnO}_{4}$ has been used as an oxidant. In the later sample we observe the peaks only due to spinel phase (Mathur et al 1999) indicating the formation of $\mathrm{Mn}-\mathrm{Cr}$ ferrite. In all the samples i.e. RS1-RS6, the width of diffraction peaks reduces, however, the lines are still quite broad and the estimated particle size still lies in the range $30-40 \mathrm{~nm}$. The XRD spectra of the samples heated at $700^{\circ} \mathrm{C}$ show very interesting behaviour. As can be seen from figure 6 , in the case of sample RS1 we observe the diffraction peaks only due to $\alpha-\mathrm{Fe}_{2} \mathrm{O}_{3}$ phase while in the samples RS2, RS3 and RS6 we observe increase in the intensities of peaks due to spinel phase and decrease in intensity of the diffraction pattern due to $\mathrm{Cr}_{2} \mathrm{O}_{3} / \alpha-\mathrm{Fe}_{2} \mathrm{O}_{3}$ phase. In the case of sample RS5, we still observe diffraction peaks due to $\mathrm{Mn}-\mathrm{Cr}$ spinel ferrite phase only.

The above studies show that in case of sample RS1, with pure iron oxide, the formation of $\gamma-\mathrm{Fe}_{2} \mathrm{O}_{3}$ takes place at room temperature which on heating at $700^{\circ} \mathrm{C}$ transforms into $\alpha-\mathrm{Fe}_{2} \mathrm{O}_{3}$. This is quite usual of $\gamma-\mathrm{Fe}_{2} \mathrm{O}_{3}$. However, presence of chromium in the samples RS2, RS3, RS4 and RS6 prepared under varying oxidative environments show some very interesting behaviour wherein at $300^{\circ} \mathrm{C}$ we observe the formation of $\gamma-\mathrm{Fe}_{2} \mathrm{O}_{3}$ with very small crystallite size while $\mathrm{Cr}_{2} \mathrm{O}_{3}$ is still in amorphous state. At $450^{\circ} \mathrm{C}$ the spinel phase due to $\gamma$

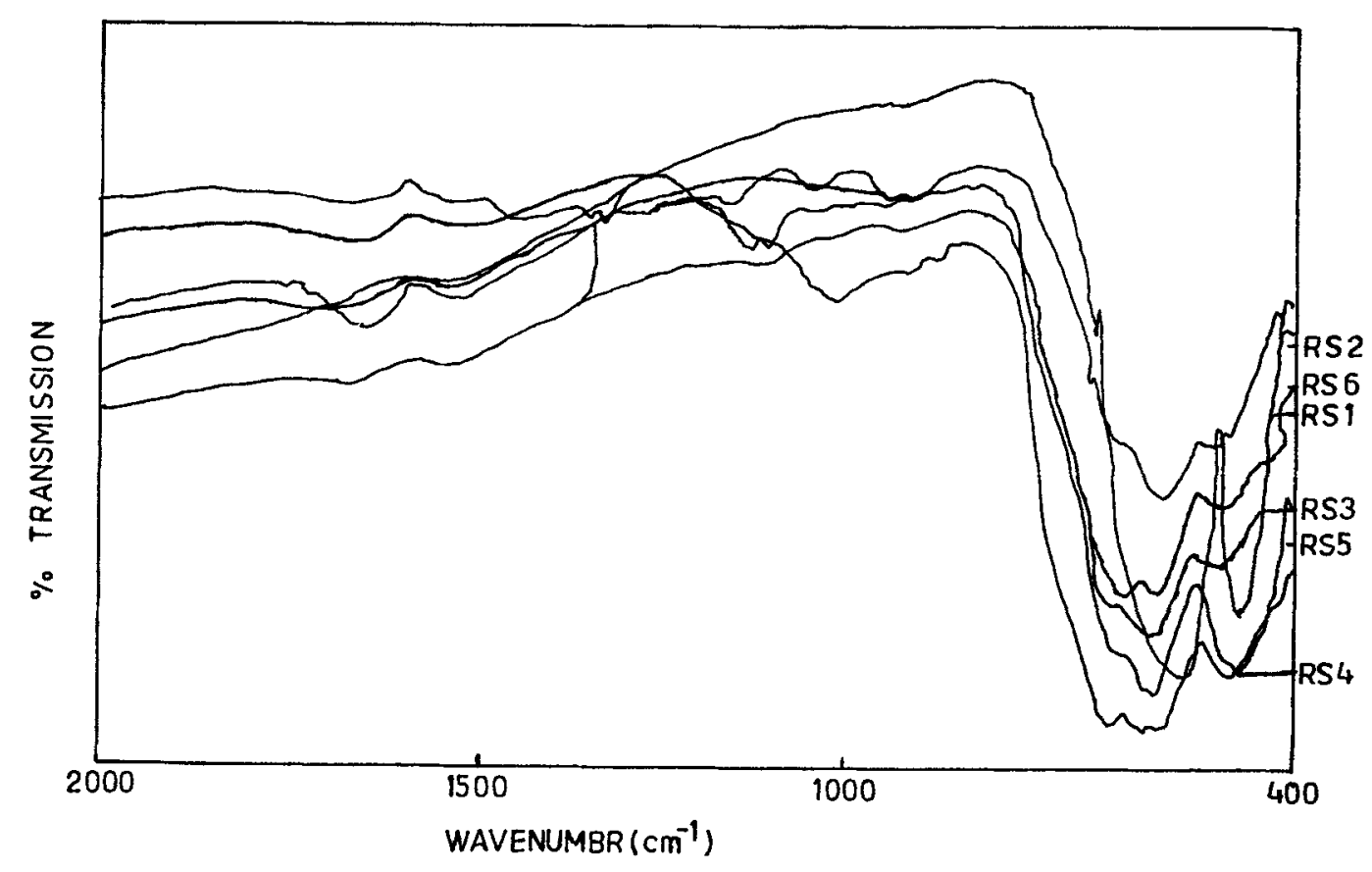

Figure 2. IR spectra of samples RS1-RS6 (heated at $450^{\circ} \mathrm{C}$ ). 


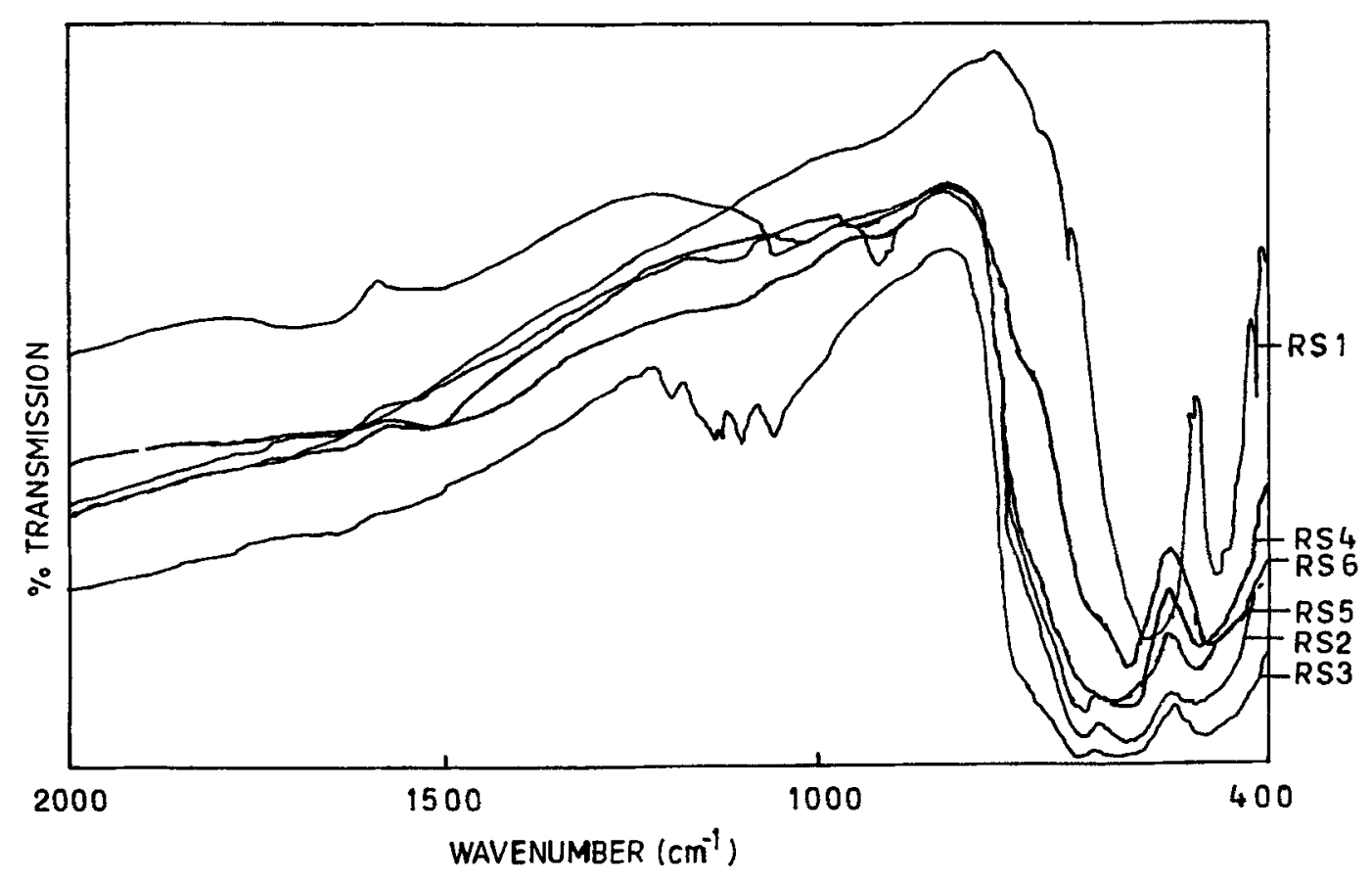

Figure 3. IR spectra of samples RS1-RS6 (heated at $700^{\circ} \mathrm{C}$ ).

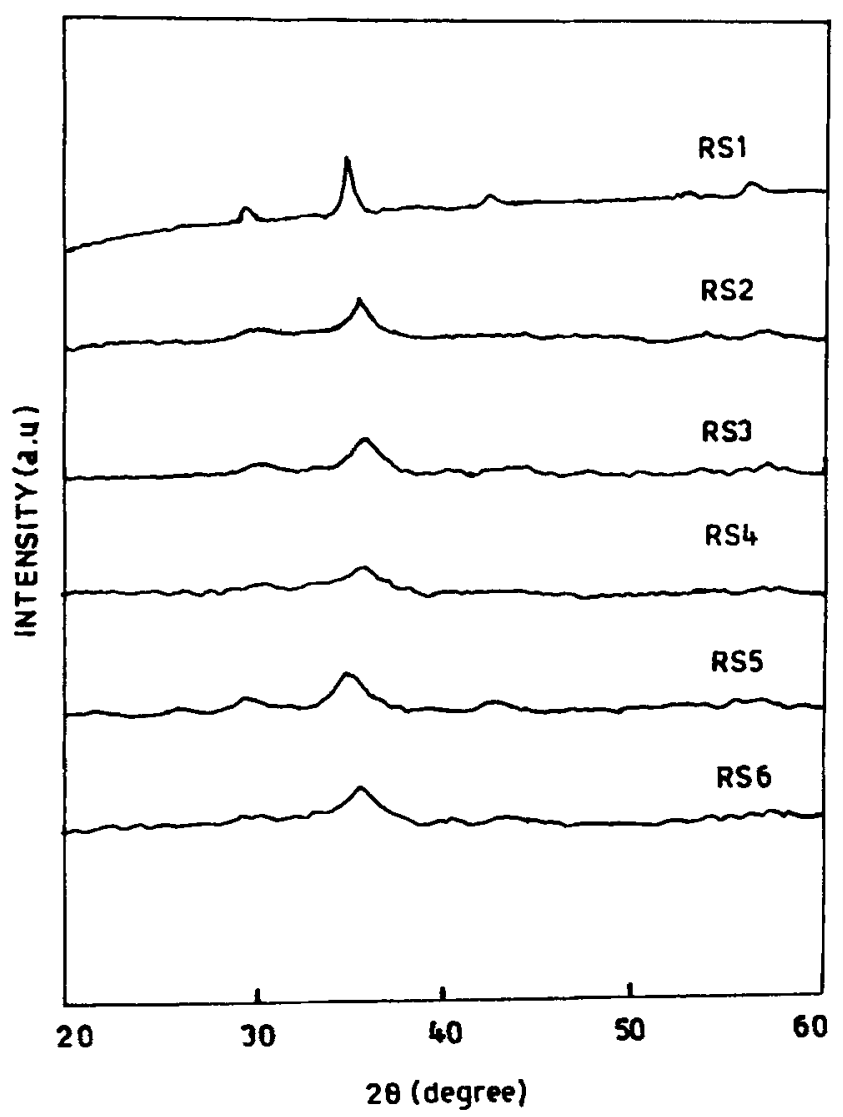

Figure 4. XRD spectra of samples RS1-RS6 (heated at $300^{\circ} \mathrm{C}$ ).
$\mathrm{Fe}_{2} \mathrm{O}_{3}$ persists and the peaks due to $\mathrm{Cr}_{2} \mathrm{O}_{3} / \alpha-\mathrm{Fe}_{2} \mathrm{O}_{3}$ phase also appear. Further heating at $700^{\circ} \mathrm{C}$ shows that intensities of the peaks due to $\mathrm{Cr}_{2} \mathrm{O}_{3} / \alpha-\mathrm{Fe}_{2} \mathrm{O}_{3}$ decrease and particularly for sample RS3 $\mathrm{Cr}_{2} \mathrm{O}_{3} / \alpha-\mathrm{Fe}_{2} \mathrm{O}_{3}$ phase disappear and only spinel phase is observed. It may be noted that both $\alpha-\mathrm{Fe}_{2} \mathrm{O}_{3}$ and $\mathrm{Cr}_{2} \mathrm{O}_{3}$ are isostructural and it is difficult to distinguish between the two from the XRD studies, however, disappearance/reduction in the intensities of the peaks due to $\mathrm{Cr}_{2} \mathrm{O}_{3} / \alpha-\mathrm{Fe}_{2} \mathrm{O}_{3}$ on heating the samples from $450^{\circ} \mathrm{C}$ to $700^{\circ} \mathrm{C}$, in the present studies rules out the possibility of formation of $\alpha-\mathrm{Fe}_{2} \mathrm{O}_{3}$ in the samples $\mathrm{RS} 2, \mathrm{RS} 3$ and RS6 as it cannot convert into $\gamma-\mathrm{Fe}_{2} \mathrm{O}_{3}$. Thus in these samples $\mathrm{Cr}_{2} \mathrm{O}_{3}$ is formed together with $\gamma-\mathrm{Fe}_{2} \mathrm{O}_{3}$. Moreover, on heating the samples RS2, RS3 and RS6 at $700^{\circ} \mathrm{C} \quad \mathrm{Cr}_{2} \mathrm{O}_{3}$ starts penetrating into $\gamma-\mathrm{Fe}_{2} \mathrm{O}_{3}$ matrix forming their solid solution. Furthermore, the possibility of formation of chromium ferrite is ruled out as both iron and chromium are in +3 oxidation state. The studies also show that the extent of reduction in the intensity of diffraction pattern due to $\mathrm{Cr}_{2} \mathrm{O}_{3}$ phase is greatly influenced by varying nature of the oxidative environment present during the preparation of the initial samples and its solubility behaviour. It can be stated (Johnson and Alexander 1986) here that in nanoparticle solute solubility may enhance due to elastic strains.

\subsection{Mössbauer studies}

The values of the computed Mössbauer parameters for all unheated and heated samples are given in table 2. From 
the table it can be seen that in case of all the unheated samples a single quadrupole doublet due to $\mathrm{Fe}^{3+}$ ions is observed (Greenwood and Gibb 1971). The higher values of QS as compared to bulk iron oxide is a clear indication of the particles to be in nanometer size $(<10 \mathrm{~nm})$ (Bhattacharya et al 1997). Further, for the samples RS2-RS6, the IS and QS values are higher as compared to those of sample RS1 containing only iron. These higher values of IS and QS are attributed to the interaction of $\mathrm{Cr}^{3+}$ ions with $\mathrm{Fe}^{3+}$ ions (Bhattacharya et al 1997). In case of samples heated at $300^{\circ} \mathrm{C}$ we continue to observe a quadrupole doublet with still higher values of QS except in sample RS1 where a six-line pattern with $H_{\text {eff }}$ value of $485 \mathrm{kOe}$, corresponding to $\gamma-\mathrm{Fe}_{2} \mathrm{O}_{3}$ (Vadera et al 1997b), is observed. The smaller $H_{\text {eff }}$ value as

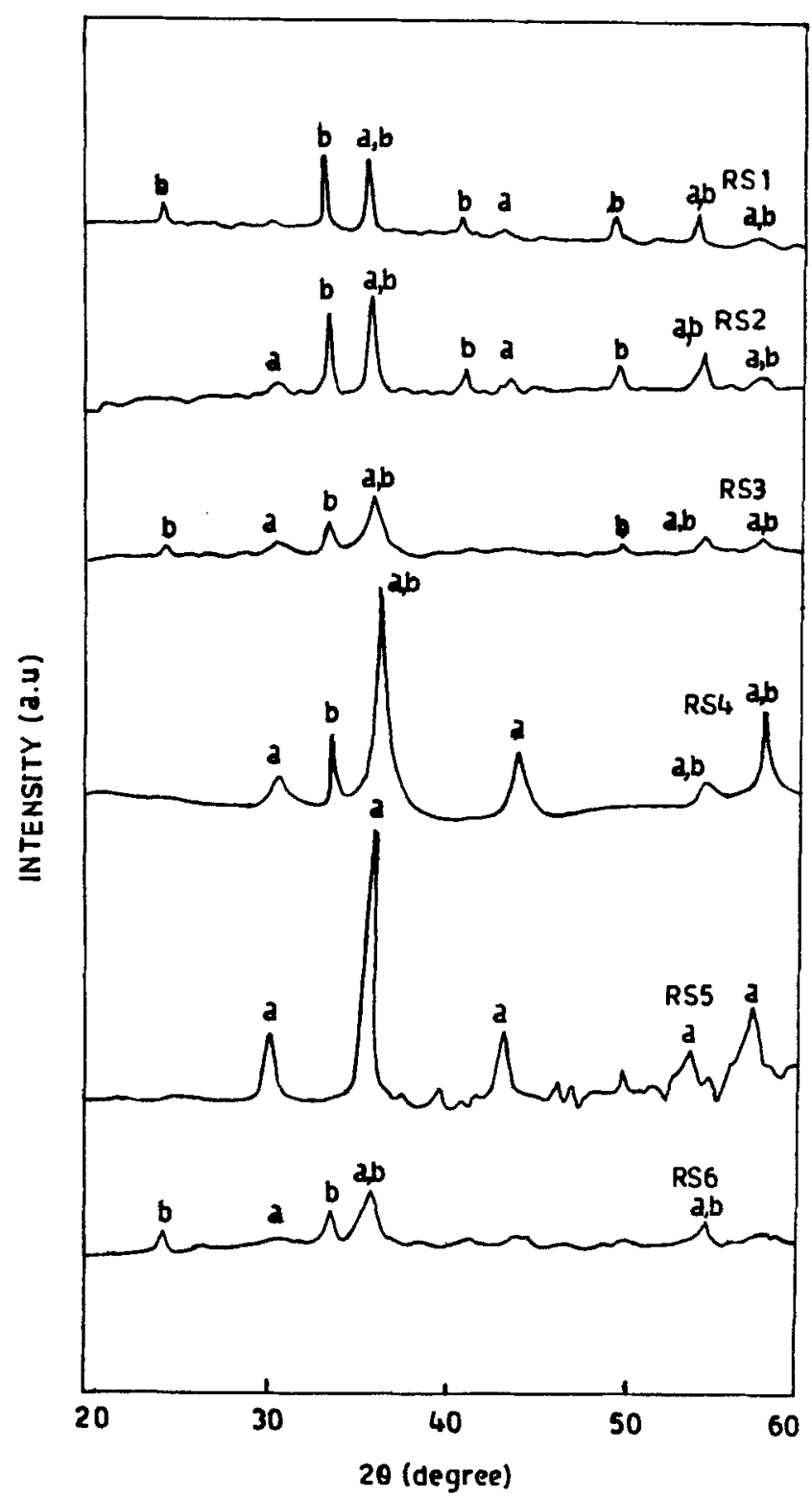

Figure 5. XRD spectra of samples RS1-RS6 (heated at $450^{\circ} \mathrm{C}$ ); (a) $\gamma-\mathrm{Fe}_{2} \mathrm{O}_{3} / \mathrm{Mn}-\mathrm{Cr}$ ferrite and (b) $\mathrm{Cr}_{2} \mathrm{O}_{3} / \alpha-\mathrm{Fe}_{2} \mathrm{O}_{3}$. compared to bulk $\gamma-\mathrm{Fe}_{2} \mathrm{O}_{3}$ is due to small particle size. The higher values of QS in the samples RS2-RS6 heated at $300^{\circ} \mathrm{C}$ indicate increased interaction between $\mathrm{Fe}^{3+}$ and $\mathrm{Cr}^{3+}$ ions due to removal of organic part on heating.

${ }^{57} \mathrm{Fe}$ Mössbauer spectra of samples heated at $450^{\circ} \mathrm{C}$ (figure 7) show very interesting behaviour. The observation of broad and relaxed spectra in all the samples, except for RS1, indicates the magnetic particles to be in nanometre range. Different degrees of relaxation is however observed for different samples depending on their reaction conditions. In case of RS1, a six-line pattern is obtained which is resolved into two sextets with $H_{\text {eff }}$ values $497 \mathrm{kOe}$ and $513 \mathrm{kOe}$ corresponding to $\gamma-\mathrm{Fe}_{2} \mathrm{O}_{3}$ and $\alpha-\mathrm{Fe}_{2} \mathrm{O}_{3}$, respectively. Definite ordering of spins is also seen in samples RS2-RS4 as two sextets could be fitted in their Mössbauer spectra. The lower effective magnetic field values below $500 \mathrm{kOe}$ (table 2) in these samples suggest the formation of only $\gamma \mathrm{Fe}_{2} \mathrm{O}_{3}$ phase.

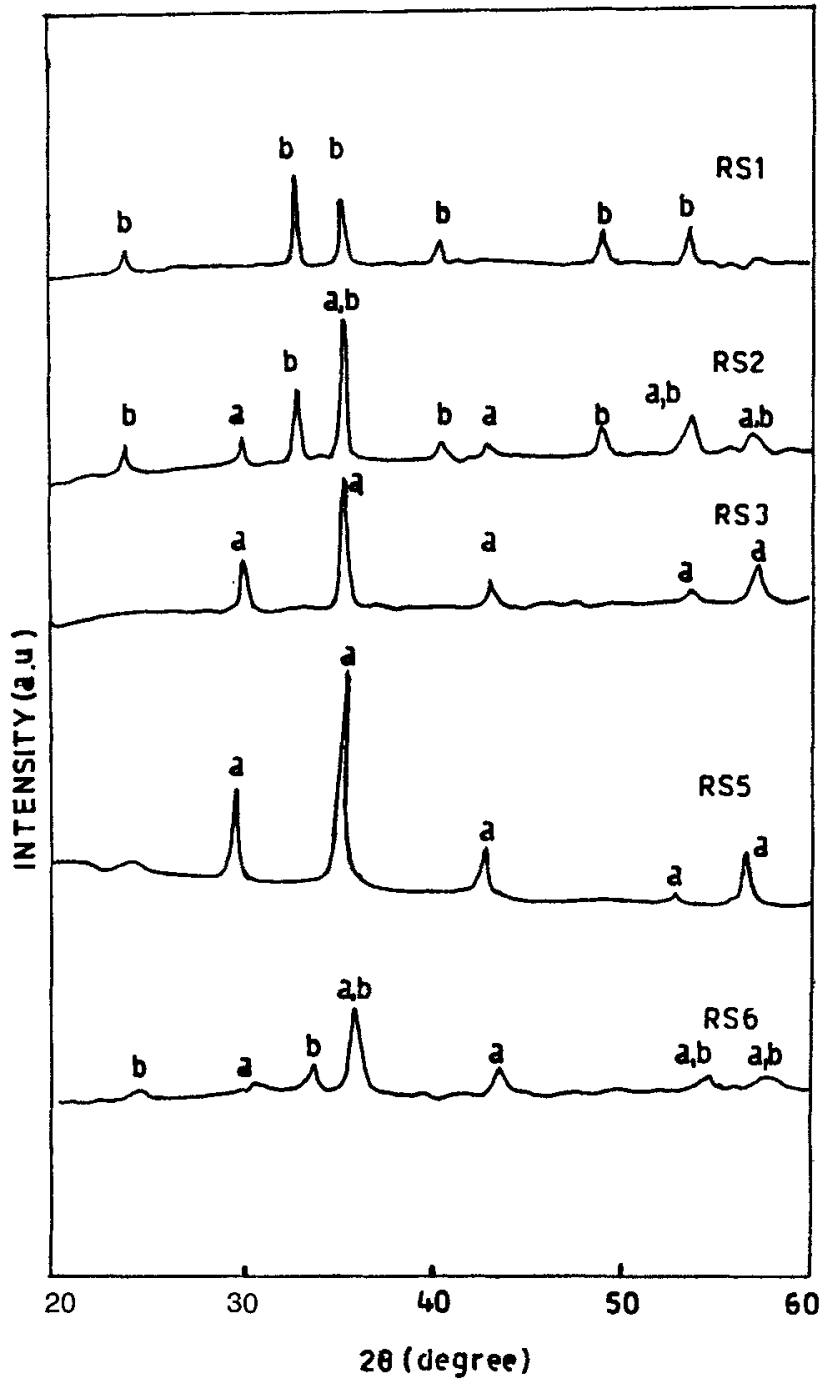

Figure 6. XRD spectra of samples RS1-RS3 and RS5-RS6 (heated at $700^{\circ} \mathrm{C}$ ); (a) $\gamma-\mathrm{Fe}_{2} \mathrm{O}_{3} / \mathrm{Mn}-\mathrm{Cr}$ ferrite and (b) $\mathrm{Cr}_{2} \mathrm{O}_{3} /$ $\alpha-\mathrm{Fe}_{2} \mathrm{O}_{3}$. 
Table 2. Mössbauer parameters for heated and unheated samples of mixed oxides of iron and chromium.

\begin{tabular}{|c|c|c|c|c|c|c|c|c|c|c|c|}
\hline \multirow[b]{2}{*}{ Sample } & \multicolumn{3}{|c|}{ Doublet } & \multicolumn{4}{|c|}{ Sextet 1} & \multicolumn{4}{|c|}{ Sextet 2} \\
\hline & $\begin{array}{c}\mathrm{IS} \\
(\mathrm{mm} / \mathrm{s})\end{array}$ & $\begin{array}{c}\mathrm{QS} \\
(\mathrm{mm} / \mathrm{s})\end{array}$ & $\begin{array}{c}\text { Area } \\
(\%)\end{array}$ & $\begin{array}{c}\mathrm{IS} \\
(\mathrm{mm} / \mathrm{s})\end{array}$ & $\begin{array}{c}\mathrm{QS} \\
(\mathrm{mm} / \mathrm{s})\end{array}$ & $\begin{array}{c}H_{\mathrm{eff}} \\
(\mathrm{kOe})\end{array}$ & $\begin{array}{l}\text { Area } \\
(\%)\end{array}$ & $\begin{array}{c}\mathrm{IS} \\
(\mathrm{mm} / \mathrm{s})\end{array}$ & $\begin{array}{c}\mathrm{QS} \\
(\mathrm{mm} / \mathrm{s})\end{array}$ & $\begin{array}{c}H_{\mathrm{eff}} \\
(\mathrm{kOe})\end{array}$ & $\begin{array}{c}\text { Area } \\
(\%)\end{array}$ \\
\hline $\mathrm{RS} 1$ - RT & 0.28 & 0.65 & 100 & - & - & - & - & - & - & - & - \\
\hline $300^{\circ} \mathrm{C}$ & - & - & - & 0.28 & -0.01 & 485 & $56 \cdot 6$ & 0.48 & 0.02 & 445 & 43.4 \\
\hline $450^{\circ} \mathrm{C}$ & - & - & - & 0.29 & -0.09 & 513 & 52.7 & 0.27 & -0.05 & 497 & $47 \cdot 3$ \\
\hline $700^{\circ} \mathrm{C}$ & - & - & - & $0 \cdot 31$ & -0.09 & 511 & 100 & - & - & - & - \\
\hline $\mathrm{RS} 2-\mathrm{RT}$ & 0.33 & 0.73 & 100 & - & - & - & - & - & - & - & - \\
\hline $300^{\circ} \mathrm{C}$ & 0.31 & 0.87 & 100 & - & - & - & - & - & - & - & - \\
\hline $450^{\circ} \mathrm{C}$ & - & - & - & 0.36 & $-0 \cdot 10$ & 494 & $34 \cdot 2$ & 0.29 & -0.09 & 466 & $65 \cdot 8$ \\
\hline $700^{\circ} \mathrm{C}$ & - & - & - & 0.33 & -0.04 & 483 & $33 \cdot 1$ & 0.33 & 0.03 & 462 & $66 \cdot 9$ \\
\hline RS3 - RT & 0.34 & 0.74 & 100 & - & - & - & - & - & - & - & - \\
\hline $300^{\circ} \mathrm{C}$ & 0.30 & 0.90 & 100 & - & - & - & - & - & - & - & - \\
\hline $450^{\circ} \mathrm{C}$ & 0.28 & 0.98 & $63 \cdot 5$ & 0.27 & 0.13 & 495 & $14 \cdot 3$ & 0.37 & 0.13 & 467 & $20 \cdot 2$ \\
\hline $700^{\circ} \mathrm{C}$ & - & - & - & 0.30 & 0.02 & 471 & 39.2 & 0.31 & -0.02 & 451 & $60 \cdot 8$ \\
\hline RS4 - RT & 0.33 & 0.73 & 100 & - & - & - & - & - & - & - & - \\
\hline $300^{\circ} \mathrm{C}$ & 0.32 & 0.87 & 100 & - & - & - & - & - & - & - & - \\
\hline $450^{\circ} \mathrm{C}$ & 0.25 & 1.34 & 29.5 & 0.33 & -0.06 & 494 & 63.9 & 0.31 & -0.10 & 410 & $36 \cdot 1$ \\
\hline $700^{\circ} \mathrm{C}$ & - & - & - & 0.31 & 0.02 & 468 & $34 \cdot 7$ & 0.30 & -0.01 & 444 & $65 \cdot 3$ \\
\hline RS5 - RT & 0.34 & 0.75 & 100 & - & - & - & - & - & - & - & - \\
\hline $300^{\circ} \mathrm{C}$ & 0.32 & 0.80 & 100 & - & - & - & - & - & - & - & - \\
\hline $450^{\circ} \mathrm{C}$ & - & - & - & 0.38 & 0.04 & 414 & $55 \cdot 7$ & 0.33 & -0.07 & 358 & $44 \cdot 3$ \\
\hline $700^{\circ} \mathrm{C}$ & - & - & - & 0.31 & 0.01 & 432 & $35 \cdot 6$ & 0.33 & 0.01 & 394 & 64.4 \\
\hline RS6-RT & 0.34 & 0.77 & 100 & - & - & - & - & - & - & - & - \\
\hline $300^{\circ} \mathrm{C}$ & 0.29 & 0.90 & 100 & - & - & - & - & - & - & - & - \\
\hline $450^{\circ} \mathrm{C}$ & 0.29 & 0.89 & 100 & - & - & - & - & - & - & - & - \\
\hline $700^{\circ} \mathrm{C}$ & - & - & - & 0.28 & -0.01 & 404 & 39.9 & 0.29 & 0.01 & 360 & $60 \cdot 1$ \\
\hline
\end{tabular}

Isomer shift values are with respect to natural iron.

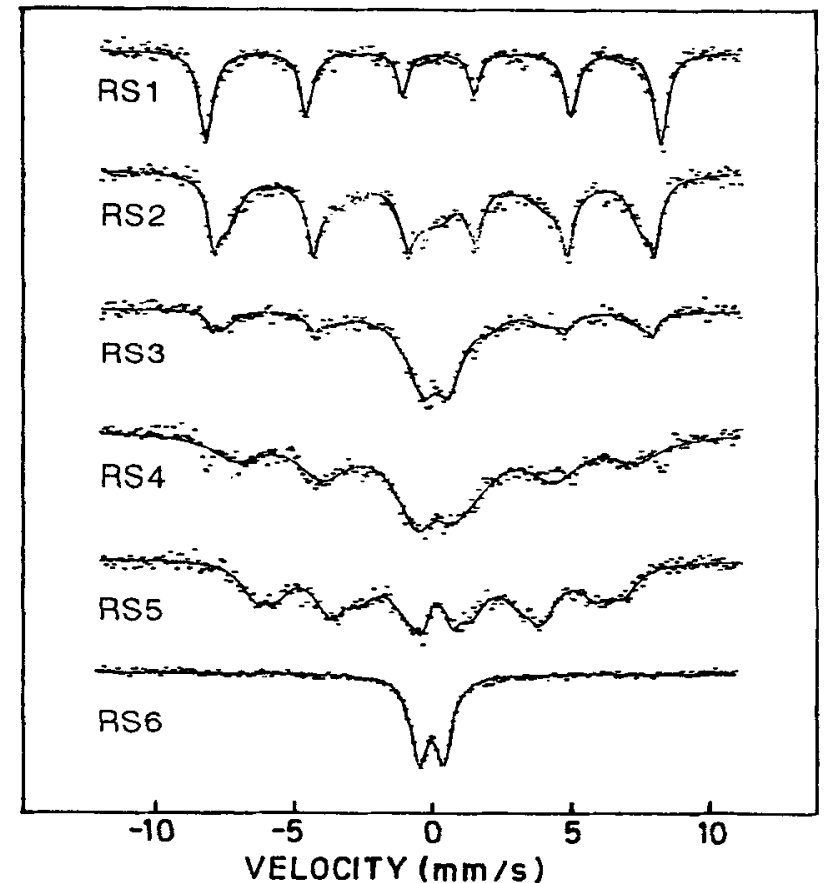

Figure 7. Room temperature ${ }^{57} \mathrm{Fe}$ Mössbauer spectra of the samples RS1-RS6 heated at $450^{\circ} \mathrm{C}$.
Further, there are considerable variations in the Mössbauer spectra of samples RS2-RS4. Though it is difficult to explain these variations, however, they might have resulted due to varying interaction between the metal oxides and the copolymer backbone or due to some changes in the copolymer backbone itself from the oxidant used for synthesis of initial samples. It has also been reported earlier that the copolymer matrix plays a very important role in bringing about the magnetic ordering of iron oxide particles (Vadera et al 1998) in the nanocomposite samples. In sample RS5 we observe two six-line patterns with $H_{\text {eff }}$ values of $414 \mathrm{kOe}$ and $358 \mathrm{kOe}$ indicating that $\mathrm{Mn}$ ions of $\mathrm{KMnO}_{4}$, used as the oxidant in the synthesis of the sample, also precipitate in the reaction to form $\mathrm{Mn}-\mathrm{Cr}$ spinel ferrite system. In the sample RS6 only a paramagnetic doublet is observed thereby suggesting no magnetic ordering in this case.

A pure six-line pattern is observed in all the samples heated at $700^{\circ} \mathrm{C}$ thereby indicating the magnetic ordering in all the samples. Further, the low effective magnetic field values $(<500 \mathrm{kOe})$ in the samples RS2-RS6, except for RS5, suggest that no $\alpha-\mathrm{Fe}_{2} \mathrm{O}_{3}$ phase is present in these samples. In the sample RS5 we continue to observe two six-line patterns due to $\mathrm{Mn}-\mathrm{Cr}$ spinel ferrite. In case 
of sample $\mathrm{RS} 1$ a six-line pattern due to $\alpha-\mathrm{Fe}_{2} \mathrm{O}_{3}$ is observed.

\section{Conclusions}

The IR, XRD and Mössbauer studies clearly indicate a definite interaction between iron and chromium ions in the as prepared samples thereby suggesting the formation of composite of the two oxides. The studies also indicate that the size of iron oxide particles in these samples is very small $<10 \mathrm{~nm}$. Further, the interaction between the metal ions increases on heating the samples at temperatures $\geq 300^{\circ} \mathrm{C}$ with formation of solid solution at $700^{\circ} \mathrm{C}$. Further, it is interesting to note from the Mössbauer and XRD studies that $\gamma-\mathrm{Fe}_{2} \mathrm{O}_{3}$ phase, which normally transforms into $\alpha-\mathrm{Fe}_{2} \mathrm{O}_{3}$ on heating at $500^{\circ} \mathrm{C}$, still persists up to $700^{\circ} \mathrm{C}$ in the present samples containing chromium ions. From IR studies it has been found that the oxidative environment exerts a strong influence on the copolymer backbone which in turn affects the solubility of $\mathrm{Cr}_{2} \mathrm{O}_{3}$ in $\gamma-\mathrm{Fe}_{2} \mathrm{O}_{3}$ on heating the samples thereby resulting into variations in their magnetic properties.

\section{Acknowledgements}

The authors are grateful to the Director, Defence Laboratory, Jodhpur for his keen interest in the present work. The authors are also thankful to Dr B B Sharma, Scientist ' $G$ ', SSPL, Delhi for help in XRD measurements and helpful discussions.

\section{References}

Azaroff L V and Buerger M J 1958 The powder method (New York: McGraw Hill Book Company, Inc.)

Bentley F F, Smithson L S and Rozek A L 1968 in Infrared spectrum and characteristic frequencies $700-300 \mathrm{~cm}^{-1}$ (New York: Interscience Pub. \& John Wiley \& Sons Inc.) p. 103

Bhattacharya A K, Hartridge A, Mallick K K, Majumdar C K, Das D and Chintalapudi S N 1997 J. Mater. Sci. 32557

Chow Moong Gan and Gonsalves E Kenneth (eds) 1996 Nanotechnology (Washington DC: The American Chemical Society)

Greenwood N N and Gibb T C 1971 Mössbauer spectroscopy (London: Chapman and Hall Ltd) p. 91

Johnson W C and Alexander J I D 1986 J. Appl. Phys. 592735

Komarneni Sridhar 1992 J. Mater. Chem. 212

Li X G, Chiba A, Takahashi S and Sato M 1998 J. Appl. Phys. 833871

Mathur R, Parihar M, Vadera S R and Kumar N 1998 J. Magn. Soc. Jap. 22 Suppl. S1 273

Mathur R, Sharma D R, Vadera S R, Gupta S R, Sharma B B and Kumar N 1999 Nanostruct. Mater. (in press)

Meerwall von E 1975 Comp. Phys. Commun. 9117

Pramanik P 1995 Bull. Mater. Sci. 18819

Shull R D 1992 Nanostruct. Mater. 183

Vadera S R, Tuli Alka, Kumar N, Sharma B B, Gupta S R, Prakash Chandra and Kishan Pran 1997a J. Phys. IV 7 C-1549

Vadera S R, Mathur R, Parihar M and Kumar N 1997b Nanostruct. Mater. 8869

Vadera S R, Parihar M, Negi S C and Kumar N 1998 in Smart materials, structures and MEMs (eds) V K Aatre, V K Varadan and V V Varadan Proc. SPIE 3321369 